\title{
Effects of physical exercises for physical and psychological problems among antenatal mothers in a district in Sri Lanka
}

I.N.S. Herath ${ }^{1 *}$, S. Sivayogan ${ }^{2}$, A. Balasuriya ${ }^{3}$

\begin{abstract}
Background

Pregnancy is a natural and normal physiological state and therefore, pregnant woman would be healthier if she remains active. Exercises can be one way to be active and are defined as any bodily activity that enhances or maintains physical fitness and overall health. Even minor physical and psychological symptoms not appropriately treated could debilitate pregnant women. The present study was undertaken to assess the importance of exercises for alleviation of physical and psychological problems among pregnant mothers.
\end{abstract}

\section{Objective}

To determine physical and psychological problems associated with pregnancy and to assess the effects of physical exercises among a group of primigravida antenatal mothers in Kegalle District, Sri Lanka.

\section{Methods}

A quasi experimental study was conducted, to implement a course of antenatal exercises, for a selected group of primigravida mothers in second trimester, in two $\mathrm{MOH}$ areas in Kegalle district. Physical and psychological problems were assessed by pre-tested interviewer administered and self administered questionnaires. Sample size was 234 each for control and intervention groups. Control and intervention groups were assessed at pre intervention, at four months during pregnancy and at six weeks post partum.

\section{Results and conclusions}

Logistic Regression analysis revealed intervention group mothers were significantly less likely to develop physical problems, psychological distress and depression compared to control group mothers. Exercised mothers were $61 \%$ less likely to deliver a low birth weight baby compared to the control group which was statistically significant (adjusted OR $=0.391 ; 95 \% \mathrm{CI} ; 0.217$ to 0.706 ; $\mathrm{p}<0.05)$.

Key words : antenatal, exercises, intervention, physical, psychological

\section{Introduction}

The pros and cons of physical exercises in pregnancy have been debated for years. There was a period when women were encouraged to remain indoors and keep themselves engaged in restricted activities during pregnancy. Later physical activity was correlated to uneventful pregnancy and labour by the physicians when they saw ease of birthing in active women.

\footnotetext{
1. Senior Registrar (Community Medicine), Health Education Bureau, Ministry of Health, Nutrition and Indigenous Medicine, Sri Lanka 2. Professor in Community Medicine, Faculty of Medical Sciences,

University of Sri Jayewardenepura, Sri Lanka

3. Senior Lecturer, Head - Department of Paraclinical Sciences, Head - Public Health and Family Medicine, Faculty of Medicine, General Sir John Kotelawala Defence University, Sri Lanka

* Correspondence: nadeeja.herath@gmail.com DOI: $10.4038 /$ jccpsl.v21i1.8072 
Worldwide, there has been a large shift towards less physically demanding work. This has been accompanied by increasing use of mechanized transportation, a greater prevalence of labour saving technology at home and less active recreational pursuits. Therefore, pregnant females at present are less active compared to their counterparts three or four decades back.

A study that was both longitudinal and cross sectional, on dynamic postural stability in pregnancy found that non exercisers were more likely to fall than those who participated in regular exercises (1). A randomized trial to assess the relationship between health related quality of life and aerobic exercises during pregnancy (2), revealed that three months supervised exercise programme improves health related quality of life. In the study conducted by Gjestland et al (3), it was revealed that antenatal mothers who exercised more than three times per week for more than 20 minutes at moderate intensity were less likely to report pelvic girdle pain.

Hormone levels are constantly fluctuating during pregnancy and in the post partum period which can lead to feelings of anxiety, depression, sadness, elation and even confusion (6). The woman may gain weight, skin may stretch out and change colour, and also, hair may fallout after pregnancy, which will give rise to emotional disturbances. In a study conducted in Ratnapura district in Sri Lanka (7), postpartum psychological distress was detected in $44.9 \%$ of mothers. Another study carried out in the Puttalam district in Sri Lanka (8) revealed that $32.1 \%$ of mothers suffer from post partum depression. As explained by Monga et al (6), the women who exercise during pregnancy can have more energy, have higher spirit and feel more relaxed. A cross sectional study carried out among the general population (9), in Finland revealed that individuals who exercised at least two to three times a week experienced significantly less depression, anger, cynical distrust and stress than those exercising less frequently or not at all.

Therefore, the objective was to implement a course of antenatal exercises for a selected group of primigravida mothers in the second trimester and to evaluate its physical and psychological benefits compared with a control.

\section{Methods}

A quasi experimental study to assess the effects of antenatal physical exercises was carried out at two non adjacent, Medical Officers of Health $(\mathrm{MOOH})$ areas in Kegalle district in Sri Lanka. This was to minimize dilution effect as there was likelihood that the mothers in the intervention group would mix-up with mothers in the control group if the same or nearby $\mathrm{MOH}$ was taken.

Mothers in the second trimester who attended antenatal clinics at $\mathrm{MOH}$ Galigamuwa and Dehiowita were considered for the study population. MOH Galigamuwa was considered as the study group and $\mathrm{MOH}$ Dehiowita was considered as the control group. Mothers in intervention group were matched to control group by age factor and level of education $(10,11)$.

Inclusion criteria - Primigravida mothers in second trimester with the consent of the attending Obstetrician for physical exercises (second trimester - thirteen to twenty-eight weeks of period of gestation).

Exclusion criteria - Primigravida mothers with contraindications for physical exercises (congestive cardiac failure, active myocardial disease, valvular heart disease, severe hypertension, thrombophlebites) and/or consent not given by Obstetrician.

The intervention group and control group were calculated using statistical method for qualitative 
outcome (12). A study was conducted by Mørkved et al(13), to assess pelvic floor muscle training on urinary incontinence. They found that intervention group was 33\% less likely to develop urinary incontinence at 36 weeks pregnancy and $39 \%$ less likely at 3 months postpartum relative to control group. Therefore $35 \%$ was considered as effect size with exercises and $50 \%$ without any intervention. Alpha and beta errors were 0.05 and 0.1 respectively. After calculation of sample size, it was rounded to 234 mothers each in the intervention and control group.

Two study instruments were used to collect data. An interviewer administered questionnaire was used to obtain baseline data and physical problems (Record sheet to mark physical symptoms experienced during fourteen days was given to mark as and when the mother developed the symptom and kept ready for interview). Two self administered questionnaires were used to assess psychological problems. They were General Health Questionnaire with 30 items (GHQ 30) and Edinburgh Postpartum Depression Scale (EPDS). GHQ 30 was translated and validated for Sri Lanka primary care attendees by Rodrigo as cited by Attygalle (7), and used by Attygalle (7) in postpartum mothers and EPDS was validated and used among antenatal and postnatal mothers by Rowel (8) in Sri Lanka.

Assessment at first and second post intervention levels - after four months from the start of intervention during pregnancy and after six weeks from delivery respectively were by the use of similar instruments used at pre intervention survey. Baseline data which was obtained during pre-intervention level was not taken during the two post intervention stages. A record sheet for outcome of pregnancy obtained details about mode of delivery, weight of baby and APGAR scores at the second post intervention level.

Six Public Health Midwives each was taken as
Field Investigators (FIs), from the two selected $\mathrm{MOOH}$ areas.

In the intervention study the mother who was willing to participate, was given the relevant documents to be taken to the Obstetrician at the government or private hospital she was attending for consultations, to get permission for antenatal physical exercises. If the consultant Obstetrician had consented, the mother was told to bring her husband and come on the following clinic visit to learn the exercises (if spouse was not available she was told to bring the next of kin who was at home with her). About five to ten eligible and willing mothers were selected to participate in the study from a clinic on one day. FIs would demonstrate the exercise steps to the couples, explaining each carefully. The precautions that had to be taken prior to and during exercises were all explained as well. The mothers were not asked to do the exercises along with the FI, since it would create stress among them. Also, it would have an inhibitory effect for participation. This was because the mothers would have to come to the clinic either changing their usual dress code or come prepared to change the dress at the clinic, if they were to do exercises. Furthermore, the mothers and their husbands or chaperon, were allowed to ask as many questions as necessary for them to understand and clarify the exercise procedure.

The FIs carried out regular unarranged field visits to find the progress and difficulties of the exercise process. Regular exercises were defined in this study as exercises which were carried out on all days or at least three days per week for thirty minutes or more (14). The participants were given a diary to record the date and time they carried out the exercises at home.

Intervention and control groups were matched by level of education and age. Control group deferred from intervention group only by the 
exercise component. Throughout the study period they were given periodic reinforcements as well.
Ethical approval was obtained from ethical review committee of Sri Jayewardenepura Medical Faculty, Sri Lanka.

\section{Results}

Table 1 Basic socio demographic characteristics of the primi antenatal mothers in the control and the intervention groups

\begin{tabular}{llllll}
\hline Socio demographic variable & \multicolumn{2}{c}{ Control } & \multicolumn{2}{c}{ Intervention } & Significance* \\
\cline { 2 - 5 } & $\mathrm{N}=\mathbf{2 3 4}$ & $\%$ & $\mathrm{~N}=234$ & $\%$ & \\
\hline
\end{tabular}

Age at marriage in years

Up to 20

$21-25$

$26-30$

$31-35$

36 or more

Mean (SD) Range**

$\begin{array}{ccccc}26 & 11.1 & 19 & 8.1 & \\ 98 & 41.9 & 92 & 39.3 & \\ 94 & 40.2 & 102 & 43.6 & \\ 14 & 6.0 & 21 & 9.0 & \\ 2 & 0.8 & 0 & 0.0 & \mathrm{t}=0.75 \\ 25.8(6.1) & 25.4(5.4) & \mathrm{df}=466 \\ 18-37 \text { years } & & 18-35 \text { years } & \mathrm{p}>0.05\end{array}$

\section{Duration of marriage (in years)}

$$
\begin{aligned}
& \text { Up to } 1 \\
& >1 \text { to } 3 \\
& >3 \text { to } 5 \\
& >5 \text { to } 10 \\
& >10
\end{aligned}
$$

Mean (SD) Range**

$\begin{array}{ccccc}53 & 22.6 & 46 & 19.7 & \\ 148 & 62.8 & 170 & 72.6 & \\ 28 & 12.0 & 17 & 7.3 & \\ 4 & 1.7 & 1 & 0.4 & \\ 1 & 0.9 & 0 & 0.0 & \mathrm{t}=2.4 \\ 3.9(5.2) & 2.8(4.5) & \mathrm{df}=466 \\ 5 \text { months }-12 \text { years } & \text { 7 months - 10 years } & \mathrm{p}>0.05\end{array}$

\section{Ethnicity of mothers}

$\begin{array}{lccccc}\text { Sinhala } & 202 & 86.3 & 208 & 88.9 & \chi^{2}=1.1 \\ \text { Tamil } & 21 & 9.0 & 19 & 8.1 & \mathrm{df}=2 \\ \text { Muslim } & 11 & 4.7 & 7 & 3.0 & \mathrm{p}>0.05\end{array}$

\section{Religion of mothers}

$\begin{array}{lccccc}\text { Buddhist } & 197 & 84.2 & 205 & 87.6 & \chi^{2}=2.8 \\ \text { Christian } & 10 & 4.3 & 5 & 2.1 & \\ \text { Hindu } & 16 & 6.8 & 17 & 7.3 & \\ \text { Islam } & 11 & 4.7 & 7 & 3.0\end{array}$




\begin{tabular}{|c|c|c|c|c|c|}
\hline \multirow[t]{2}{*}{ Socio demographic variable } & \multicolumn{2}{|c|}{ Control } & \multicolumn{2}{|c|}{ Intervention } & \multirow[t]{2}{*}{ Significance* } \\
\hline & $\mathbf{N}=\mathbf{2 3 4}$ & $\%$ & $\mathrm{~N}=\mathbf{2 3 4}$ & $\%$ & \\
\hline \multicolumn{6}{|l|}{ Occupation } \\
\hline Professionals & 8 & 3.4 & 9 & 3.8 & $\chi^{2}=0.05$ \\
\hline Clerical & 15 & 6.4 & 17 & 7.3 & $\mathrm{df}=1$ \\
\hline Service \& sales workers & 0 & 0.0 & 9 & 3.8 & $\mathrm{p}>0.05$ \\
\hline Agricultural/ Fisheries & 3 & 1.3 & 3 & 1.3 & \\
\hline Crafts \& related trade & 4 & 1.7 & 3 & 1.3 & \\
\hline $\begin{array}{l}\text { Elementary occupation } \\
\text { (labourer) }\end{array}$ & 15 & 6.4 & 7 & 3.0 & \\
\hline Housewives & 189 & 80.8 & 186 & 79.5 & \\
\hline $\begin{array}{l}\text { Mean age of mothers (SD) } \\
\text { range }\end{array}$ & $\begin{array}{r}26.5 \\
18-3\end{array}$ & $\begin{array}{l}6.8) \\
\text { years }\end{array}$ & $\begin{array}{r}26 . \\
18-3\end{array}$ & $\begin{array}{l}6.3) \\
\text { years }\end{array}$ & $\begin{array}{c}t=0.66 \\
d f=466 \\
p>0.05\end{array}$ \\
\hline \multicolumn{6}{|l|}{ Level of education } \\
\hline Grade 6 - 10 & 45 & 19.2 & 45 & 19.2 & $\chi^{2}=0.00$ \\
\hline Grade 11 - 12 & 151 & 64.5 & 151 & 64.5 & $\mathrm{df}=2$ \\
\hline Higher education & 38 & 16.2 & 38 & 16.2 & \\
\hline
\end{tabular}

\footnotetext{
* Comparison between control and intervention groups

** Within group comparison
}

The mean age at marriage in the control group was 26 years whereas it was 25years in the intervention group. However, there was no statistically significant difference between the two groups. The mean duration of marriage in the control group was four years whereas it was three years in the intervention group and a statistically significant association seen between the two groups. There was no statistically significant difference between control and intervention group by ethnicity, religion or occupation. Furthermore, there was no statistically significant difference found, among the two groups of mothers on age category and level of education since those variables were matched. 
Table 2 Number of mothers that complained of some physical problem among control and intervention groups

\begin{tabular}{lccccc}
\hline Stage & Control & & Intervention & Significance $\neq$ \\
\hline Pre intervention & $\mathbf{N}=\mathbf{2 3 4}$ & $\mathbf{\%}$ & $\mathbf{N}=\mathbf{2 3 4}$ & $\mathbf{\%}$ & \\
Present & 172 & 73.5 & 168 & 71.8 & $\chi^{2}=0.097$ \\
Absent & 62 & 26.5 & 66 & 28.2 & $\mathrm{df}=1$ \\
& & & & & $\mathrm{p}>0.05$
\end{tabular}

\section{Post intervention after}

\section{4 months}

Present

Absent

\section{Post intervention at}

\section{6 weeks \\ postpartum}

Present

Absent
$\mathrm{N}=222$

158

$64 \quad 28.8$

$\mathrm{p}<0.05$
$\mathrm{N}=196$

113

83

57.7

42.3

$* \mathrm{p}<0.05$

$\%$

3

$\chi^{2}=7.76$

$\mathrm{df}=1$

$* \mathrm{p}<0.05$

\footnotetext{
A

$* * \mathrm{p}<0.05$

$\mathrm{p}<0.05$

* Comparison between pre intervention and post intervention after four months using Mc Nemar's $\chi^{2}$

**Comparison between pre intervention, post intervention after four months and post intervention at six weeks post-partum using Cochran's $\mathrm{Q}$ test ( $\mathrm{df}=2$ )

$\neq$ Comparison between control and intervention groups at each stage of intervention
}
30.6
$* * \mathrm{p}<0.05$

$66 \quad 47.8$

$\chi^{2}=10.03$

$\mathrm{df}=1$

When all physical symptoms were considered, at the beginning of our study there was no significant difference between the control and intervention groups $\left(\chi^{2}(1)=0.097, \mathrm{p}>0.05\right)$. However, there was a significant difference between the control and intervention groups at four months post intervention during pregnancy $\left(\chi^{2}(1)=7.76, p<0.05\right)$ and at six weeks postpartum level $\left(\chi^{2}(1)=10.03, p<0.05\right)$. There was a significant difference in the control group and intervention group separately (Mc Nemar's $\chi^{2}$ $\mathrm{p}<0.05$; Cochran's $\mathrm{Q}$ test $\mathrm{p}<0.05, \mathrm{df}=2$ ) at four months post intervention level during pregnancy and at six weeks postpartum level as well, which can be attributed to physical exercises. We can see that the reduction of presentation of symptoms in the intervention group had resulted in these significant changes.

Logistic Regression was performed to ascertain the effects of status of employment and exercise intervention on the development of physical problems. Intervention group mothers were $75 \%$ less likely to develop physical problems compared to control group and it was statistically significant (adjusted OR $=0.254 ; 95 \%$ CI 0.161 to $0.401 ; \mathrm{p}<0.05)$. 
Table 3 Psychological distress measured using GHQ - 30 among control and intervention groups

\begin{tabular}{lccccc}
\hline Stage & \multicolumn{2}{c}{ Control } & \multicolumn{2}{c}{ Intervention } & Significance $\neq$ \\
\hline Pre intervention & $\mathrm{N}=234$ & $\%$ & $\mathrm{~N}=234$ & $\%$ & \\
Present $(>5)$ & 56 & 23.9 & 52 & 22.2 & $\chi^{2}=0.1$ \\
Absent $(\leq 5)$ & 178 & 76.1 & 182 & 77.8 & $\mathrm{df}=1$ \\
& & & & & $\mathrm{p}>0.05$
\end{tabular}

\section{Post intervention after}

4 months

Present (>5)

Absent $(\leq 5)$
$\mathrm{N}=222$

47

175
$\%$

21.2

78.8

$* \mathrm{p}>0.05$

$\begin{array}{cc}\mathrm{N}=196 & \% \\ 20 & 10.2 \\ 176 & 89.8 \\ & * \mathrm{p}<0.05\end{array}$

$\chi^{2}=8.5$

$\mathrm{df}=1$

$\mathrm{p}<0.05$

\section{Post intervention at}

\section{6/52 postpartum}

Present (>5)

Absent $(\leq 5)$

\section{$\mathrm{N}=219$}

44

175

** $\mathrm{p}>0.05$
$\%$

$\mathrm{N}=138$

12

126

91.3

$* * \mathrm{p}<0.05$
8.7

$\%$

$\chi^{2}=7.5$

$\mathrm{df}=1$

* Comparison between pre intervention and post intervention after four months using Mc Nemar's $\chi^{2}$

**Comparison between pre intervention, post intervention after four months and post intervention at six weeks post-partum using Cochran's $\mathrm{Q}$ test ( $\mathrm{df}=2$ )

‡Comparison between control and intervention groups at each stage of intervention

There was $24 \%$ who had psychological distress in the pre intervention level which decreased to $21 \%$ in the four months post interventional level in control group whereas, $22 \%$ in the pre intervention level has decreased to $10 \%$ in the intervention group.

This decrease in the psychological distress at post intervention level when compared to pre intervention level was statistically not significant $(p>0.05)$ in the control whereas it was significant $(\mathrm{p}<0.05)$ in the intervention group.

Psychological distress was reduced to $20 \%$ in the control group and to $9 \%$ in the intervention group at post intervention level at six weeks postpartum.

There was no statistically significant difference $(p>0.05)$ seen in control group, but, there was a statistically significant difference $(p<0.05)$ in the intervention groups across the three time points.

There was no statistically significant difference $(p>0.05)$ in the presentation of psychological distress between the control and intervention groups at pre intervention level, but, a statistically significant difference $(p<0.05)$ was seen in the post intervention levels at four months in pregnancy and at six weeks post-partum.

Status of employment and exercise intervention were taken as predictors for psychological distress. It was found that exercised mothers were $63 \%$ less likely to develop psychological distress compared to the control group which was statistically significant (adjusted $\mathrm{OR}=0.371$ 95\% CI 0.187 to $0.733 ; \mathrm{p}<0.05$ ). 
Table 4 Depression in the antenatal mother measured using EPDS among control and intervention groups

\begin{tabular}{lccccc}
\hline Stage & Control & \multicolumn{3}{c}{ Intervention } & Significance $\neq$ \\
\hline Pre intervention & $\mathbf{N}=\mathbf{2 3 4}$ & $\mathbf{\%}$ & $\mathbf{N}=\mathbf{2 3 4}$ & $\mathbf{\%}$ & \\
Present $(>9)$ & 24 & 10.3 & 29 & 12.4 & $\chi^{2}=0.3$ \\
Absent $(\leq 9)$ & 210 & 89.7 & 205 & 87.6 & $\mathrm{df}=1$ \\
& & & & & $\mathrm{p}>0.05$
\end{tabular}

Post intervention after

$\begin{array}{lccccc}4 \text { months } & \mathrm{N}=222 & \% & \mathrm{~N}=196 & \% & \\ \text { Present }(>9) & 37 & 16.7 & 17 & 8.7 & \chi^{2}=5.2 \\ \text { Absent }(\leq 9) & 185 & 83.3 & 179 & 91.3 & \mathrm{df}=1 \\ & * \mathrm{p}>0.05 & * \mathrm{p}>0.05 & \mathrm{p}<0.05 \\ & & & & & \\ \text { Post intervention at } & & & & & \\ \text { 6/52 postpartum } & \mathrm{N}=219 & \% & \mathrm{~N}=138 & \% & \\ \text { Present }(>9) & 39 & 17.8 & 12 & 8.7 & \chi^{2}=5.0 \\ \text { Absent }(\leq 9) & 180 & 82.2 & 126 & 91.3 & \mathrm{df}=1 \\ & * * \mathrm{p}>0.05 & * * \mathrm{p}<0.05 & \mathrm{p}<0.05\end{array}$

* Comparison between pre intervention and post intervention after four months using Mc Nemar's $\chi^{2}$

**Comparison between pre intervention, post intervention after four months and post intervention at six weeks post-partum using Cochran's $\mathrm{Q}$ test ( $\mathrm{df}=2$ )

$\neq$ Comparison between control and intervention groups at each stage of intervention

There was $10 \%$ with depression in the pre intervention level which had increased to $17 \%$ at post intervention at four months level in the control group whereas, $12 \%$ in the pre intervention level has reduced to $9 \%$ in the intervention group. Proportion of participants with depression at pre intervention level compared to post interventional at four months was statistically not significant $(\mathrm{p}>0.05)$ in both intervention and control groups.

At six weeks post-partum depression was seen in $18 \%$ in the control group whereas it had reduced to $9 \%$ in the intervention group. There was no statistically significant difference $(p>0.05)$ in the increase of percentage of mothers who had depression across the three time points in the control group whereas, the reduction of presentation of depression was statistically significant $(p<0.05)$ in the intervention group.
There was no statistically significant difference $(p>0.05)$ in the presentation of depression between the control and intervention groups at pre intervention level, but, a statistically significant difference $(p<0.05)$ was seen in the post intervention levels at four months in pregnancy and at six weeks post-partum.

ALogistic Regression was performed to ascertain the effects of status of employment and exercise intervention on the development of depression. Intervention group (exercised) mothers were $58 \%$ less likely to develop depression compared to control group mothers and it was statistically significant (adjusted OR $=0.424 ; 95 \%$ CI 0.212 to $0.848 ; \mathrm{p}<0.05)$. 
Table 5. Birth weight of the new born babies of the primi mothers in the control and the intervention groups

\begin{tabular}{|c|c|c|c|c|c|}
\hline \multirow{2}{*}{$\begin{array}{l}\text { Birth outcome } \\
\text { Pre intervention }\end{array}$} & \multicolumn{2}{|c|}{ Control } & \multicolumn{2}{|c|}{ Intervention } & \multirow[t]{2}{*}{ Significance $\ddagger$} \\
\hline & $\mathrm{N}=219$ & $\%$ & $\mathrm{~N}=138$ & $\%$ & \\
\hline \multirow{2}{*}{\multicolumn{6}{|c|}{$\begin{array}{l}\text { Birth weight of } \\
\text { new born (in kg) }\end{array}$}} \\
\hline & & & & & \\
\hline$<2.5$ & 58 & 26.5 & 17 & 12.3 & $\mathrm{t}=2.4$ \\
\hline $2.5-4$ & 159 & 72.6 & 120 & 87.0 & $\mathrm{df}=355$ \\
\hline$>4$ & 2 & 0.9 & 1 & 0.7 & $\mathrm{p}<0.05$ \\
\hline$* *$ Mean $(\mathrm{SD})$ & \multicolumn{2}{|c|}{$2.85(0.84)$} & \multicolumn{2}{|c|}{$1.75-4.25 \mathrm{~kg}$} & \\
\hline Range & \multicolumn{2}{|c|}{$3.05(0.63)$} & \multicolumn{2}{|c|}{$1.95-4.1 \mathrm{~kg}$} & \\
\hline
\end{tabular}

Mean birth weight in the control group was $2.85 \mathrm{~kg}$ whereas it was $3.05 \mathrm{~kg}$ in the intervention group. There were $27 \%$ low birth weight babies (less than $2.5 \mathrm{~kg}$ ) in the control group compared to $12 \%$ in the intervention group. There was a statistically significant association $(p<0.05)$ in the birth weights of babies born to control and intervention group mothers where a less number of low birth weight babies were born to mothers in the intervention group. Status of employment and exercise intervention were taken as predictors for birth weight. It was found that exercised mothers were $61 \%$ less likely to deliver a low birth weight baby compared to the control group which was statistically significant (adjusted OR $=0.39195 \%$ CI 0.217 to 0.706 ; $\mathrm{p}<0.05$ ).

\section{Discussion}

The two main reasons for attrition was mother leaving the area for delivery of baby and dislike to participate in the study. However, more than $90 \%$ in the control group and nearly $60 \%$ in the intervention group were available for assessment at the final post intervention survey. In the study conducted by Gjestland et al(3) in Norway revealed that, only $14.6 \%$ adhere to current exercise guideline which was more than three times per week for more than 20 minutes at moderate intensity. Therefore, $60 \%$ can be considered as a good achievement in this intervention study as maternal exercises is still not a very famous and popular option in Sri Lanka.

When missing data was analyzed there was no significant difference between age and type of occupation in the antenatal mothers who did not continue in the intervention and those who completed it. However, we found a statistically significant difference $(\mathrm{p}<0.05)$ among more educated mothers continuing in the intervention study compared to those educated up to grade 10 level.

The physical symptoms that were considered for discussion were fatigue, PGP/ PLBP, musculoskeletal pain, urinary incontinence, varicose veins, nausea and vomiting and headache. Although other minor symptoms were present they were solved with time and therefore could not be followed. Furthermore, physical problems selected for discussion were considered likely to be alleviated by physical exercises. The reduction of presentation of overall physical 
symptoms in the intervention group resulted in significant changes. Arizabaleta et al (2) in their randomized controlled trial showed similar results.

When psychological distress was considered, there was no significant difference between control and intervention groups at the start of the study but, there were significant differences at the two post intervention levels. In the study conducted by Goodwin et al (15) using GHQ28 , had shown that exercised group had a lower psychological distress level as compared to the control group which was similar to the findings of our study. It was further confirmed, in the study by Beddoe et al(16) who examined mindfulness based yoga intervention during pregnancy to assess efficacy in reducing psychological distress.

When depression was considered, Shivakumar et al(17) gave similar results to our study, in their systematic literature review using English language articles published in several databases from 1985 to January 2010. Demissie et al(18), measured depression using Center for Epidemiological Studies - Depression (CES-D) scale and found that depressive symptoms were less in active women compared to inactive women thus again confirming our study results. It was shown in Songøygard et al (19) that there was a reduction in depressive symptoms in mothers who start to exercise anew. This may be the reason for our intervention study to get a positive result of reduction of depression with antenatal physical exercises.

In the present study we had observed a statistically significant difference in the birth weight among control and intervention group mothers. These findings were similar to the findings by Schramm et al (20) in Missouri, Abeysena (21) in Sri Lanka and, Takito et al (22) in Brazil where exercises were found to be beneficial.

However, in the experimental study of Forouhari et al (23) birth weight was found to have no statistically significant difference although there was $42.7 \mathrm{~g}$ average increased birth weight in the experimental group compared to control. In the randomized controlled trial conducted by Haakstad et al (24) in Norway, revealed that there was no statistically significant difference in mean birth weight, low birth weight or macrosomia in the exercised compared to non exercised mothers. In these studies, they had randomized the same group of mothers to exercising and non-exercising groups whereas our study was a quasi experimental study. Therefore, it can be postulated that there was contamination effect in Haakstad et al (24) and Forouhari et al (23) which may have resulted in a different inference from other studies. Furthermore, differences in the exercises taught and socio-cultural differences also may have contributed to the failure to portray a positive result for exercises and birth weight in these studies.

\section{Conclusions and recommendations}

Physical exercises for sixteen weeks during pregnancy in primi antenatal mothers significantly reduce overall physical problems, psychological distress and depression level and reduces of low birth weight. An exercise programme approved by a consultant obstetrician should be practiced by all healthy primi antenatal mothers for physical and psychological benefits.

\section{Acknowledgements}

We are very grateful to all the families who took part in this study, the public health midwives for their help in recruiting the mothers, and the whole team, which includes interviewers, computer and laboratory technicians, clerical workers, volunteers, and nurses. Also, we would like to thank the Health Education Bureau for the support given.

\section{Conflict of Interest}

There are no conflicts of interest. 


\section{References}

1. Crory Mc, J.L., Chambers, A.J., Daftray, A. and Refdern, M.S. Dynamic postural stability in pregnant fallers and non fallers. British Journal of Obstetrics and Gynaecology, 2010; 117(8):954-62.

2. Arizabaleta, A.V.M., Buitrago, L.O., de Plata, A.C.A., Escudero, M.M. and Ramírez-Vélez, R. (2010). Aerobic exercise during pregnancy improves health-related quality of life: a randomized trial. Journal of Physiotherapy 2010 56, $253-258$.

3. Gjestland, K., Bø, K., Owe, K.M. and Eberhard-Gran, M. (2013). Do pregnant women follow exercise guidelines? Prevalence data among 3482 women, and prediction of low-back pain, pelvic girdle pain and depression. British Journal of Sports Medicine 2013; 47: 515 - 520.

4. Mantle, J., Haslam, J. and Barton S. Physiotherapy in Obstetrics and Gynaecology (2nd ed.) Edinburgh: Elsevier science Ltd., 2004.

5. Tendais, I., Figueiredo, B., Mota, J. and Conde, A. (2011). Physical activity, healthrelated quality of life and depression during pregnancy. Cadernos de Saúde Pública, 2011; 27(2): 219 - 228.

6. Monga, A. and Baker, P.N. Obstetrics by Ten Teachers (18th ed.). London: Hodder Arnold, 2006.

7. Attygalle, D.E. Incidence of selected postpartum morbidities and their correlates in Ratnapura district (Doctoral thesis). Post Graduate Institute of Medicine, Colombo, Sri Lanka, 2002.
8. Rowel, D.D.S. Prevalence, incidence \& correlates of postpartum depression in the Puttalam district (Doctoral thesis). Post Graduate Institute of Medicine, Colombo, Sri Lanka, 2004.

9. Hassmen, P., Koivula, N. and Uutela, A. Physical exercise and psychological wellbeing: A Population Study in Finland. Preventive Medicine 2000; 30 (1), 17 25.

10. Hennekens, C.H. and Buring, J.E. Epidemiology in medicine Philadelphia: Lippincott Williams and Wilkins, 1987.

11. Hulley, S.B. and Cummings, S.R. Designing clinical research; An epidemiological approach (2nd ed.). Philadelphia: Lippincott Williams and Wilkins, 2001.

12. Pocock, S.J. Clinical Trials, A Practical Approach. Cornwall: John Wiley \& Sons Ltd., 1991.

13. Mørkved, S., Bø, K., Schei, B. and Salvesen, K.A. Pelvic floor muscle training during pregnancy to prevent urinary incontinence: A single-blind randomized controlled trial. The American College of Obstetricians and Gynaecologists 2003; 101 (2): 313 - 319.

14. Artal, R. and O'Toole, M. (2003). Guidelines of the American College of Obstetricians and Gynecologists for exercise during pregnancy and the postpartum period. British Journal of Sports Medicine 2003; 37: 6-12.

15. Goodwin, A., Astbury, J. and McMeeken, J.Body image and psychological wellbeing in pregnancy; A comparison of 
exercisers and non-exercisers. Australian and New Zealand Journal of Obstetrics and Gynaecology, 2000; 40(4): 442 - 447.

16. Beddoe, A.E., Yang, C.P., Kennedy HP, Weiss SJ and Lee KA. The effects of mindfulness-based Yoga during pregnancy on maternal psychological and physical distress. Journal of Obstetric, Gynecologic, \& Neonatal Nursing 2009; 38(3), 310-319. doi: 10.1111/j.15526909.2009.01023.x

17. Shivakumar, G., Brandon, A.R., Snell, P.G., Santigo-Munoz, P., Jhonson, N.L., Trivedi, M.H. and Freeman, M.P. Antenatal Depression: A rationale for studying exercise. Depression and anxiety 2011; 28(3), 234-242.

18. Demissie, Z., Siega-Riz, A.M., Evenson, K.R., Herring, A.H., Dole, N. and Gaynes, B.N. Physical activity and depressive symptom among pregnant women: The PIN3 study. Archives of Women's mental health 2011; 14(2): 145-157.

19. Songøygard, K.M., Stafne, S.N., Evensen, K.A.I., Salvesen, K.A., Vik, T. andMørkved, S. Does Exercise during pregnancy prevent postnatal depression?. Acta obstetricia et gynecologica scandinavica 2012; 91: 62 67.

20. Schramm, W.F., Stockbauer, J.W. and Hoffman, H.J. Exercise, employment, other activities and adverse pregnancy outcomes. American Journal of Epidemiology 1996; 143 (3): 211 - 218.

21. Abeysena, C. The effect of physical activity and psychosocial stress on pregnancy outcome (Doctoral thesis). Post Graduate Institute of Medicine, Colombo, Sri Lanka, 2002.
22. Takito, M.Y. and Benício, M.H.D. Physical activity during pregnancy and fetal outcomes: a case-control study. Revista de Saúde Pública 2010; 44(1): 90-101.

23. Forouhari, S., Yazdanpanahi, Z., Parsanezhad, M.E. and Raigan-Shiraz, M. (2009). The effects of regular exercises on pregnancy outcome. Iranian Red Crescent Medical Journal 2009; 11(1): 57 - 60.

24. Haakstad, L.A.H. and Bø, K. Exercise in pregnant women and birth weight: a randomized controlled trial. Bio Med Central Pregnancy and Childbirth 2011; 11: 66 . 